\title{
Mesoscale modelling study of the interactions between aerosols and PBL meteorology during a haze episode in China Jing-Jin-Ji and its near surrounding region - Part 2: Aerosols' radiative feedback effects
}

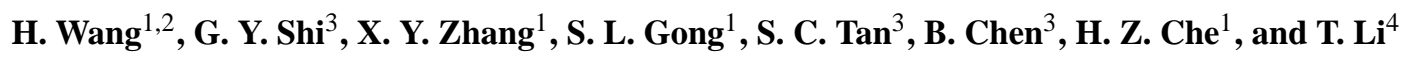 \\ ${ }^{1}$ Institute of Atmospheric Composition, Key Laboratory of Atmospheric Chemistry of the China Meteorological \\ Administration, Chinese Academy of Meteorological Sciences (CAMS), Beijing 100081, China \\ ${ }^{2}$ Collaborative Innovation Center on Forecast and Evaluation of Meteorological Disasters, Nanjing University of Information \\ Science \& Technology, Nanjing 210044, China \\ ${ }^{3}$ State Key Laboratory of Numerical Modeling for Atmospheric Sciences and Geophysical Fluid Dynamics, Institute of \\ Atmospheric Physics, Chinese Academy of Sciences, Beijing 100029, China \\ ${ }^{4}$ School of Atmospheric Physics, Nanjing University of Information Science \& Technology, Nanjing 210044, China
}

Correspondence to: H. Wang (wangh@cams.cma.gov.cn, wangh@ rays.cma.gov.cn)

Received: 24 September 2014 - Published in Atmos. Chem. Phys. Discuss.: 14 November 2014

Revised: 13 February 2015 - Accepted: 17 February 2015 - Published: 23 March 2015

\begin{abstract}
Two model experiments, namely a control (CTL) experiment without aerosol-radiation feedbacks and a experiment with online aerosol-radiation (RAD) interactions, were designed to study the radiative feedback on regional radiation budgets, planetary boundary layer (PBL) meteorology and haze formation due to aerosols during haze episodes over Jing-Jin-Ji, China, and its near surroundings (3JNS region of China: Beijing, Tianjin, Hebei, East Shanxi, West Shandong and North Henan) with a two-way atmospheric chemical transport model. The impact of aerosols on solar radiation reaching Earth's surface, outgoing long-wave emission at the top of the atmosphere, air temperature, PBL turbulence diffusion, PBL height, wind speeds, air pressure pattern and $\mathrm{PM}_{2.5}$ has been studied focusing on a haze episode during the period from 7 to 11 July 2008. The results show that the mean solar radiation flux that reaches the ground decreases by about $15 \%$ in $3 \mathrm{JNS}$ and 20 to $25 \%$ in the region with the highest aerosol optical depth during the haze episode. The fact that aerosol cools the PBL atmosphere but warms the atmosphere above it leads to a more stable atmospheric stratification over the region, which causes a decrease in turbulence diffusion of about $52 \%$ and a decrease in the PBL height of about $33 \%$. This consequently forms a positive feedback on the particle concentration within the
\end{abstract}

PBL and the surface as well as the haze formation. Additionally, aerosol direct radiative forcing (DRF) increases PBL wind speed by about $9 \%$ and weakens the subtropical high by about $14 \mathrm{hPa}$, which aids the collapse of haze pollution and results in a negative feedback to the haze episode. The synthetic impacts from the two opposite feedbacks result in about a $14 \%$ increase in surface $\mathrm{PM}_{2.5}$. However, the persistence time of both high $\mathrm{PM}_{2.5}$ and haze pollution is not affected by the aerosol DRF. On the contrary over offshore China, aerosols heat the PBL atmosphere and cause unstable atmospheric stratification, but the impact and its feedback on the planetary boundary layer height, turbulence diffusion and wind is weak, with the exception of the evident impacts on the subtropical high.

\section{Introduction}

Aerosol direct radiative forcing (DRF) arises from the reforming of the Earth-atmosphere radiation budget by the absorption and scattering of solar radiation and the absorption and the emission of thermal radiation. This may cool or heat the Earth-atmosphere system, leading to the reforming of the 
Earth-atmosphere temperature profile and impacts on global and regional climate, which has been widely noted and studied (Hansen et al., 1997; Ramanathan et al., 2001; Liao et al., 2006; Yu et al., 2006; Huang et al., 2006a, b, 2009; Che et al., 2014).

Considering the short lifetime of most aerosol particles (about 1 week) and their sharp uneven local and regional distribution and high dependence on emission sources and local meteorological conditions in the lower atmosphere (Che et al., 2007, 2009; Huang et al., 2007, 2008; Wang et al., 2014), aerosol effects on smaller spatial and temporal atmospheric scales may be worthy of greater attention. Studies at regional or local scales have shown that the DRF due to aerosols can exceed, in terms of intensity, the DRF attributable to greenhouse gases and lead to complex and important feedback mechanisms at such scales (Ramanathan, 2001; Li et al., 2007; Shindell and Faluvegi, 2009). The radiative feedback and impacts on mesoscale weather due to aerosol DRF have caused widespread concern in recent years. Certain studies have been conducted to simulate the impact on mesoscale weather circulation and to evaluate the possible feedback on short- and medium-range weather and numerical prediction in different regions of the world (Grell et al., 2005; Fast et al., 2006; Perez et al., 2006; Wang and Christopher, 2006; Wang et at al., 2010a, b; Heinold et al., 2008; Chapman et al., 2009). However, the current understanding of aerosol effects on weather contains major uncertainties because the interactions among aerosols, meteorology, radiation and chemistry are very complex and require further study using the online coupled models.

Aerosols are the main pollutants when haze episodes occur in China and $\mathrm{PM}_{10}$ may reach up to $1000 \mu \mathrm{m}^{-3}$ in the $3 \mathrm{JNS}$ (Beijing, Tianjin, Hebei, East Shanxi, West Shandong and North Henan) region of China (Zhang et al., 2013; Wang et al., 2014) during severe, long-lasting hazy weather. Aerosol particles suspended in local atmosphere lead to significant DRF and impacts on local or regional circulation as well as on the developing process of hazy weather. The meteorological condition of the planetary boundary layer (PBL) has important impacts on the occurrence, persistence, dissipation and pollution density of the haze (Vogelezang et al., 1996; Santanello et al., 2005; Cheng et al., 2002; Pleim, 2007). Substantial aerosols may also influence PBL meteorology and circulation and, in turn, evidently affect the haze and air pollution process by its DRF since most aerosol particles concentrate in PBL during haze events.

Focusing on July 2008 and a haze episode from 7 to 11 July in 3JNS, an external mixing scheme of seven kinds of aerosols has been introduced into the GRAPES/CUACE model to evaluate the optical features of composite aerosols and discuss PBL aerosol loading, the PBL meteorological properties closely related to haze and their relationship to haze episodes (Part 1 of the companion paper, Wang et al., 2015). In this article, the aerosol optical properties are used as input parameters in a radiative transfer scheme where the radiative heating rates are fed back to the online dynamic frame of the GRAPES/CUACE. This allows us to evaluate aerosol DRF and its impact on the local radiation budget and the PBL meteorological features including air temperature, heating/cooling profile rates, wind intensity, planetary boundary layer height (PBLH), turbulence diffusion and air pressure pattern over 3JNS.

\section{Model introduction}

The dynamic core, physics processes option, chemical frame including emission sources, gas and aerosol processes, and interaction between gas and aerosols in the GRAPES/CUACE model have been introduced in Part 1 (Wang et al., 2015). This section provides a brief description of the radiative transfer scheme used in this research.

Several radiative transfer modes can be selected in the GRAPES/CUACE model. The short-wave (SW) and longwave (LW) radiative transfer models developed by the Climate and Radiation Branch, NASA/Goddard Space Flight Center (CLIRAD-SW and CLIRAD-LW) (Chou et al., 1998, 2001), are used in this work for their convenience and fine capacity in processing aerosols (Wang et al., 2010, 2013). The CLIRAD includes the absorption due to water vapour, $\mathrm{O}_{3}, \mathrm{O}_{2}, \mathrm{CO}_{2}$, clouds and aerosols. Interactions among the absorption and scattering by clouds and aerosols are considered. The solar spectrum in the CLIRAD is divided into 11 bands and the thermal infrared spectrum into 10 bands from 3.333 to $40 \mu \mathrm{m}$. For each atmospheric layer and spectral band, the effective optical thickness, single scattering albedo and asymmetry factor are summered up over all gases and particles:

$$
\begin{aligned}
& \tau=\sum_{i} \tau_{i}, \\
& \bar{\omega}=\sum_{i} \omega_{i} \tau_{i} / \sum_{i} \tau_{i}, \\
& \bar{g}=\sum_{i} g_{i} \omega_{i} \tau_{i} / \sum_{i} \tau_{i} \omega_{i},
\end{aligned}
$$

where $i$ denotes ozone, water vapour, clouds, aerosols and atmospheric gases. Aerosol optical depth (AOD) $\left(\tau_{\mathrm{a}}\right)$, single scattering albedo $\left(\omega_{\mathrm{a}}\right)$ and Asymetry factor $\left(g_{\mathrm{a}}\right)$ are calculated by an external mixing scheme of different types of aerosols as described in the companion paper (Part 1, Wang et al., 2015). The effect of aerosols on solar and thermal radiation within the GRAPES/CUACE model is realized by implementing $\tau_{\mathrm{a}}, \omega_{\mathrm{a}}$ and $g_{\mathrm{a}}$ into the CLIRAD radiation scheme. The radiative heating/cooling rates in the atmosphere, including aerosol absorption and scattering of solar and infrared radiation, were calculated and fed back to the thermal and dynamic processes at every radiation step in the 
GRAPES/CUACE model. The online active interaction of "meteorology-aerosol-radiation" is completely achieved in the model, and the radiative feedback on the local PBL and the haze due to aerosols is studied using the model.

\section{Experiment design}

The control (CTL) experiment is the base simulation without calculating aerosol radiative feedback and impacts online as described in Part 1 (Wang et al., 2015). In this paper, the simulation experiment (online active interacting meteorologyaerosol-radiation) is referred to as the RAD experiment. The only difference between the RAD and CTL experiments is that in the RAD experiment, the aerosol radiation heating/cooling effect is calculated online and fed back to the model thermodynamic and dynamic processes.

In the following section, the simulation results of surface radiative fluxes from the RAD experiment are compared with those of the CTL simulation as a way to assess the aerosol impact on the local Earth-atmosphere radiation balance. The differences between the RAD and CTL experiments concerning the PBL meteorological fields, including PBL temperature, height, turbulence diffusion, meteorological pattern and pollutant particle loading, will be discussed as part of the study of aerosol radiative effects and feedback on local PBL thermal and dynamic processes. Finally, the aerosol impact on the haze episode itself is discussed.

The haze episode that occurred during 7-11 July 2008 was selected for this study. All model configuration options and model parameters adopted were the same as those used in the CTL experiment in Part 1 (Wang et al., 2015). The initial fields and lateral boundary data on the meteorology and tracers, together with the model domain, horizontal and vertical resolutions and both step and forecasting, also matched those used in the CTL experiment.

\section{The impacts on the regional radiation budget}

The solar radiation flux reaching the Earth's surface may change obviously due to aerosols absorbing and scattering of solar radiation during the haze episode. A large number of particles suspended in the atmosphere, as well as infrared radiation and the outgoing long-wave radiation at the top of atmosphere (TOA), may also be changed. This leads to the reforming of regional Earth-Atmosphere radiation budget. The key factor impacting radiation flux is the aerosol AOD. It can be seen in Fig. 1 that the averaged simulated AOD during 7-11 July shows an expected coherence with MODIS Deep Blue AOD at 550 in horizontal distribution, affected area, peak values and their geographical locations over 3JNS, and downwind area even though MODIS omits parts of the data in 3JNS. The land domain $\left(111-119^{\circ} \mathrm{E}, 33-40^{\circ} \mathrm{N}\right.$ named as LAND in Fig. 1) with the highest AOD values is regarded as the most representative of $3 \mathrm{JNS}$; the aerosol impacts on
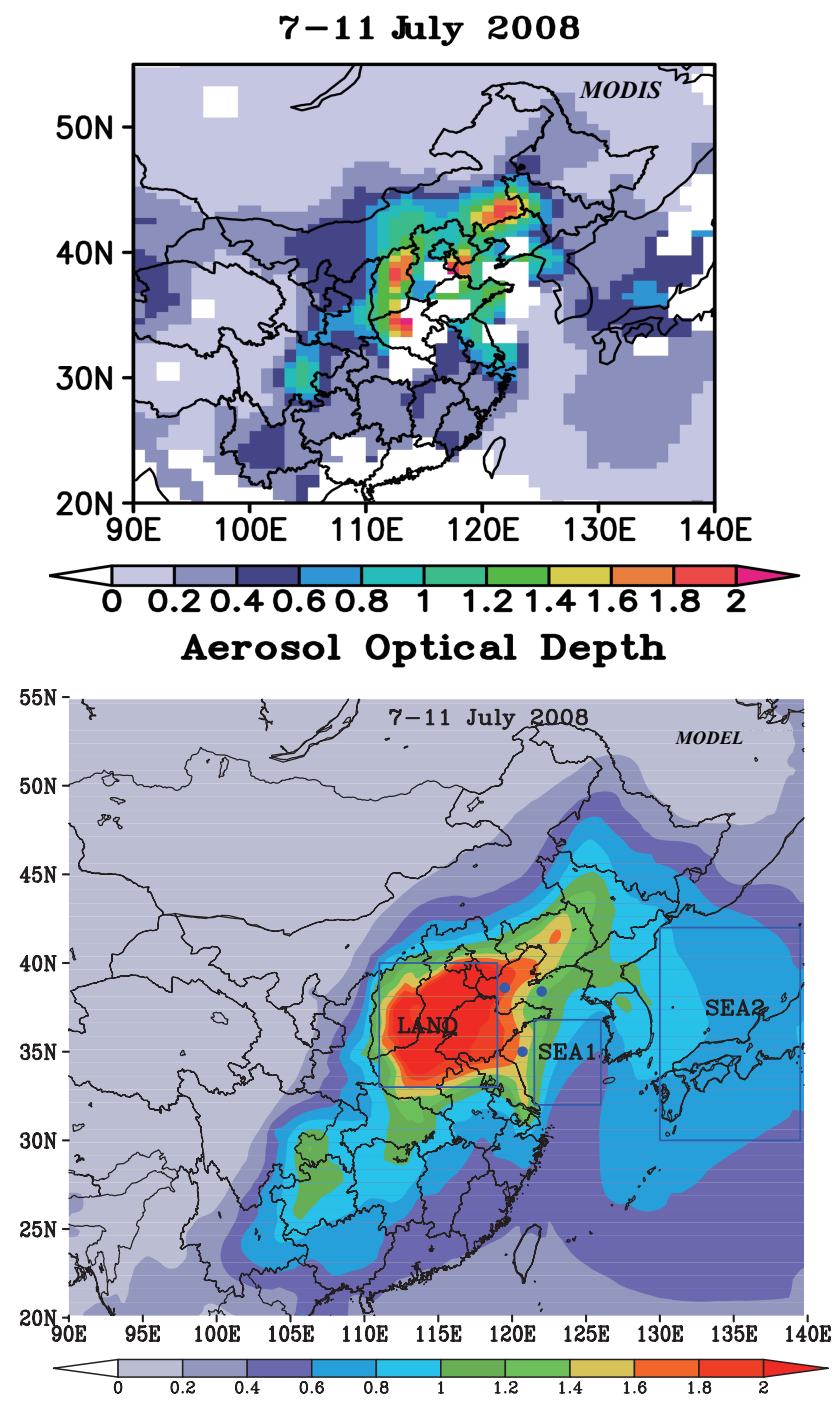

Figure 1. The averaged MODIS (top) and modelled AOD (bottom) during the period of 7-11 July 2008: LAND represents the polluted area in 3JNS; points A, B and C represent offshore China; domains SEA1 and SEA2 refer to China's Huang Sea and the Sea of Japan.

meteorological fields are presented in the following sections. The three points labelled A $\left(38.6^{\circ} \mathrm{N}, 119.5^{\circ} \mathrm{E}\right), \mathrm{B}\left(35.0^{\circ} \mathrm{N}\right.$, $\left.120.7^{\circ} \mathrm{E}\right)$ and $\mathrm{C}\left(38.4^{\circ} \mathrm{N}, 122.0^{\circ} \mathrm{E}\right)$ in Fig. 1 are selected to represent China's offshore region. SEA1 $\left(32.0\right.$ to $36.8^{\circ} \mathrm{N}$, 121.5 to $126.0^{\circ} \mathrm{E}$ ) denotes the sea area from the eastern coast of China to the western edge of the Korean peninsula, while SEA2 (30.0 to $42.0^{\circ} \mathrm{N}, 130.0$ to $139.5^{\circ} \mathrm{E}$ ) represents the sea area to the east of the Korean peninsula. 
The percentage change in surface SW flux due to aerosol DRF at the surface (SFC) and change in LW at TOA are defined as

$\Delta F_{\mathrm{SFC}}=\left(\operatorname{Flux}\left(\downarrow_{\mathrm{Solar}, \mathrm{SFC}}\right)_{\mathrm{RAD}}-\operatorname{Flux}\left(\downarrow_{\text {Solar, SFC }}\right)_{\mathrm{CTL}}\right)$

$/$ Flux $\left(\downarrow_{\text {Solar }, \text { SFC }}\right)_{\mathrm{CTL}} \times 100 \%$,

$\Delta F_{\mathrm{TOA}}=\left(\operatorname{Flux}\left(\uparrow_{\mathrm{IR}, \mathrm{TOA}}\right)_{\mathrm{RAD}}-\operatorname{Flux}\left(\uparrow_{\mathrm{IR}, \mathrm{TOA}}\right)_{\mathrm{CTL}}\right)$

/Flux $\left(\uparrow_{\text {IR,TOA }}\right)_{\mathrm{CTL}} \times 100 \%$,

where $\operatorname{Flux}\left(\downarrow_{\text {Solar,SFC }}\right)_{\text {RAD }}$ and Flux $\left.\left(\downarrow_{\text {Solar,SFC }}\right)_{\text {CTL }}\right)$ represent the downward solar radiation flux $\left(w / \mathrm{m}^{2}\right)$ at the surface of the RAD and CTL experiment respectively. Flux $\left(\uparrow_{\text {IR,TOA }}\right)_{\text {RAD }}$ and Flux $\left(\uparrow_{\text {IR, TOA }}\right)_{\text {CTL }}$ are the infrared radiation fluxes emitted from Earth at TOA in the RAD and CTL experiments respectively. Figure 2a displays the averaged $\Delta F_{\mathrm{SFC}}$ at 06:00 UTC from 7 to 11 July. It can be seen that aerosol DRF decreased more than $15 \%$ of the solar radiation fluxes reaching the ground over most of 3JNS; the decrease reached up to $20-25 \%$ in the most polluted area with the highest AOD values. This result indicates the important impact of aerosol DRF on ground and near-ground radiation budgets. Figure $2 \mathrm{~b}$ shows the mean $\Delta F_{\mathrm{TOA}}$ during 7-11 July, indicating that aerosol DRF reduced only $1-3 \%$ of infrared emission at the TOA during this haze episode, which is far lower than the surface downward solar radiation flux change. This result suggests that aerosol DRF has more important impacts on the ground and near-Earth surface radiation budgets, i.e. on the PBL energy budget, than on TOA.

\section{The radiative feedback on PBL meteorology due to aerosols}

The remarkable reforming of the surface and PBL radiation energy budget by aerosols will certainly lead to changes in PBL thermodynamics, dynamics and physical processes, which result in changes in PBL meteorological fields and further the haze development. The impacts on air temperature, turbulence distribution, PBLH, wind speed, air pressure and $\mathrm{PM}_{2.5}$ due to aerosols will be discussed in the following sections.

\subsection{The impacts on temperature}

The direct and initial change due to aerosol DRF is the temperature. The surface temperature change reached -1 to $-3 \mathrm{~K}$ at 06:00 UTC on 7-11 July (Fig. 3a) in 3JNS, corresponding to the highest AOD values and substantial negative values of surface SW flux changes as shown in Fig. 1. A vertical cross section of temperature was drawn along latitude $38^{\circ} \mathrm{N}$ (black line in Fig. 3a) that shows the vertical temperature change due to aerosol DRF (Fig. 3b). Also shown is the reduction by aerosol DRF of surface and PBL temperature over the land surface. A PBL temperature decrease of 1
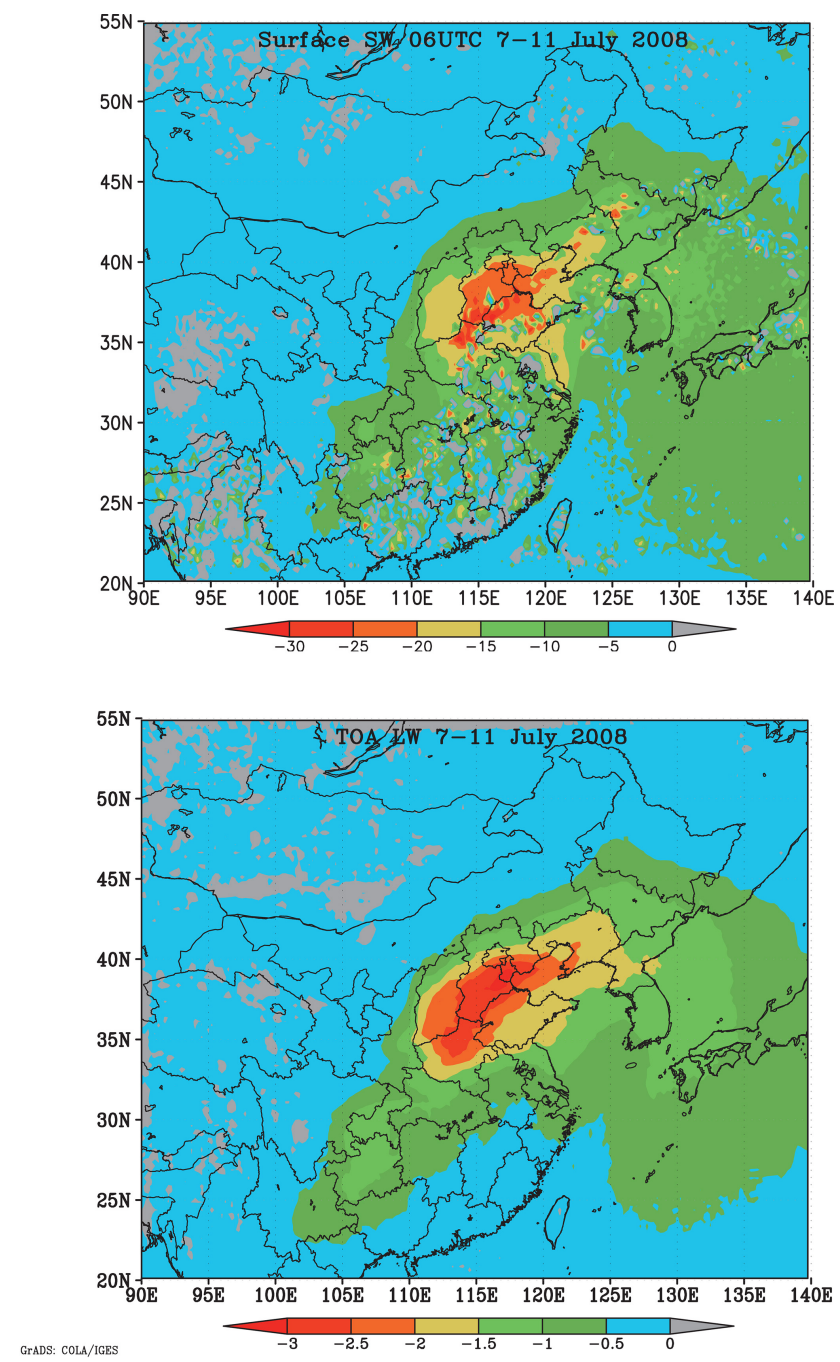

Figure 2. The percentage of change in the surface SW flux at 06:00 UTC (a) and in TOA outgoing LW flux (b) due to aerosol DRF during the 7-11 July period.

to $2 \mathrm{~K}$ occurred over the Chinese mainland $\left(110-118^{\circ} \mathrm{E}\right)$ and 0.5 to $1 \mathrm{~K}$ over the Korean peninsula $\left(125-128^{\circ} \mathrm{E}\right)$, while the aerosol impacts on the surface and PBL temperature changes were small or increased weakly over the oceanic area. Over this cooling atmospheric layer a weak warming layer exists with a vertical height ranging from 975 to $600 \mathrm{hPa}$ along latitude $38^{\circ} \mathrm{N}$. The vertical sections of regional average temperature change due to aerosols over LAND region (Fig. 3c): points A, B, C, SEA1 and SEA2 (Fig. 3d) display the vertical temperature changes over 3JNS with the highest pollution i.e. offshore China, the China Sea and the Sea of Japan. It is clear from Fig. $3 \mathrm{c}$ that temperature diminished from the surface to about $850 \mathrm{hPa}$ over $3 \mathrm{JNS}$ and then increased above that level. This suggests the presence of aerosol cooling effects on the PBL atmosphere and warming effects on the atmosphere above it, which may lead to more stable stratification of the atmosphere over this region. Points A, B and C lie offshore 

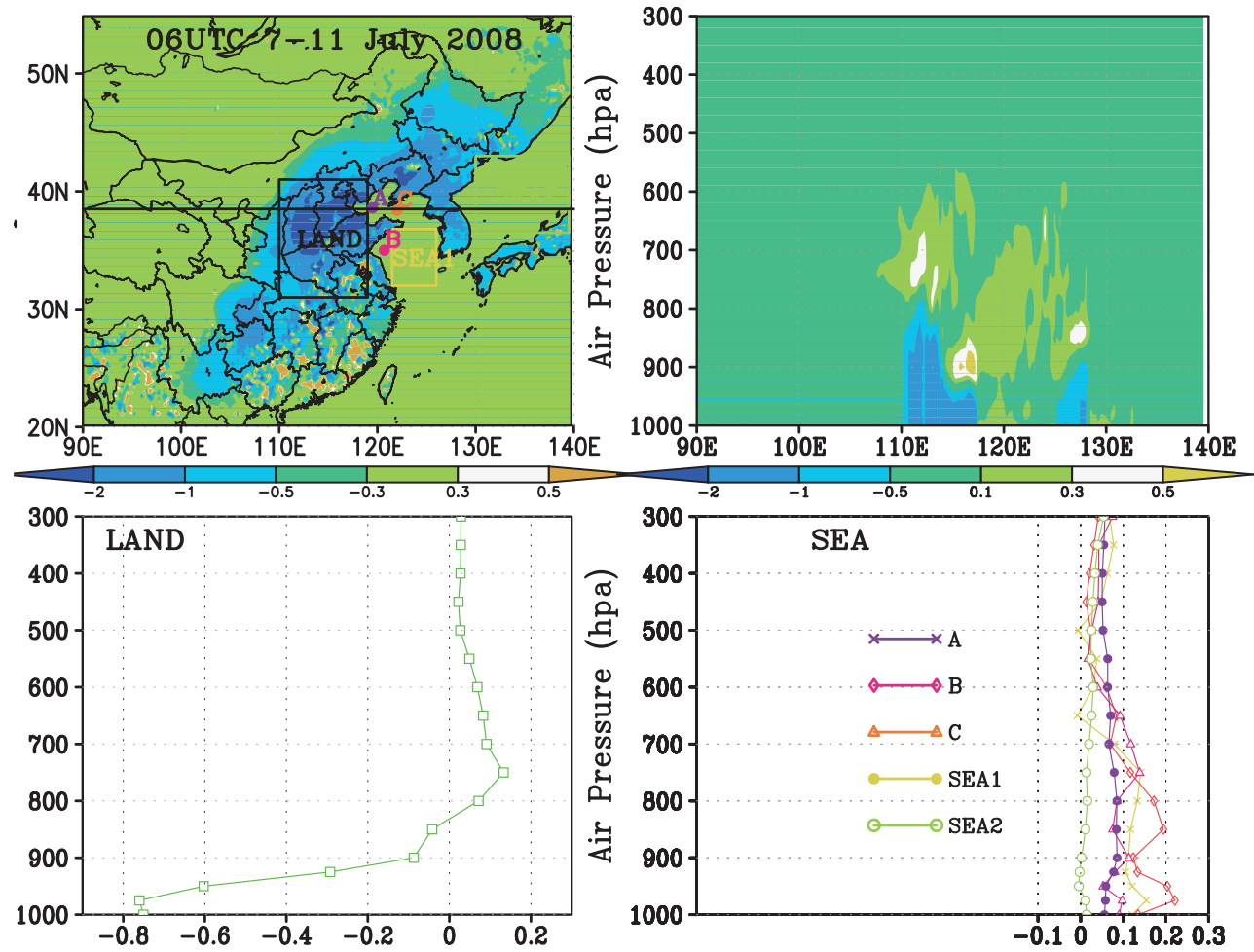

Figure 3. Mean temperature changes (K) at 06:00 UTC of 7-11 July due to aerosol DRF: (a) surface temperature; (b) vertical section at $38^{\circ} \mathrm{N}$ of (a); (c) vertical section of domain LAND region; (d) vertical section of points A, B, C, SEA1 and SEA2.

of the Chinese coast, and SEA1 represents the region near the China Sea. The vertical profiles of temperature changing induced by the aerosols' radiative feedback effect over those areas are quite different than those over the LAND region due to the different surface albedo and the height and depth of aerosols layer. It can be seen from Fig. 3d that aerosols heat the atmosphere from the surface to a height of $600 \mathrm{hPa}$ over these regions. This is especially so in the PBL atmosphere because the higher aerosol layer and the smaller AOD value may cause more unstable atmospheric stratification over the sea areas. Aerosol DRF has little impact on the surface and PBL temperatures in the SEA2 region, and only very weak warming can be found above a height of $750 \mathrm{hPa}$, owing to the lower AOD values in this region. These results and the discussion in Fig. 3 indicate that aerosol DRF led to more stable atmospheric stratification over 3JNS and to more unstable atmospheric stratification over offshore China and the China Sea regions during the haze episode of 7-11 July. This has an important influence on local PBL meteorology and the regional atmosphere circulation.

\subsection{The impacts on PBL turbulence diffusion}

Changes in regional atmospheric stratification positively result in varying turbulence diffusion. The turbulence diffusion coefficient (FKTM) used in Part 1 (Wang et al., 2015) of this study is a valid physical parameter that indicates the strength of turbulence diffusion. Figure 4 displays FKTM changes due to aerosol DRF. Figure 4a describes the regional distribution of mean impacts on turbulence diffusion in the haze from 7 to $11 \mathrm{July}$; it can be seen that low turbulence diffusion exists over the entire 3JNS region with mean FKTM values of $14-45 \mathrm{~m}^{2} \mathrm{~g}^{-1}$ in the haze conditions during 7-11 July 2008. Aerosol DRF led to a mean $5 \mathrm{~m}^{2} \mathrm{~g}^{-1}$ reduction of FKTM over most of the eastern Chinese mainland and a lessening of $10-15 \mathrm{~m}^{2} \mathrm{~g}^{-1}$ in 3JNS, showing remarkable depression on the local atmospheric turbulence diffusion process from aerosol DRF. Figure 4b displays the daily changes in the regional averaged difference: FKTM difference between the RAD and CTL experiments over LAND and SEA1 in July 2008. It is clear from Fig. 4b that the averaged FKTM of the LAND region was reduced by aerosol DRF more or less during the whole of July 2008. As with the haze event during 7-11 July 2008, the FKTM declined by about $7-9 \mathrm{~g}^{2} \mathrm{~m}^{-1}$ and $8-10 \mathrm{~g}^{2} \mathrm{~m}^{-1}$ during another haze episode during $25-28$ July 2008, which was also initiated by aerosol DRF. FKTM changes resulting from aerosol DRF also occurred over the SEA1 region but these were small to negligible in scale. These results suggest that the suppression of diffusion turbulence by aerosol DRF is both certain and significant over the middle and eastern Chinese mainland with its high pollutants while, in contrast, impact over the sea region is small and can be negligible during haze episodes. 

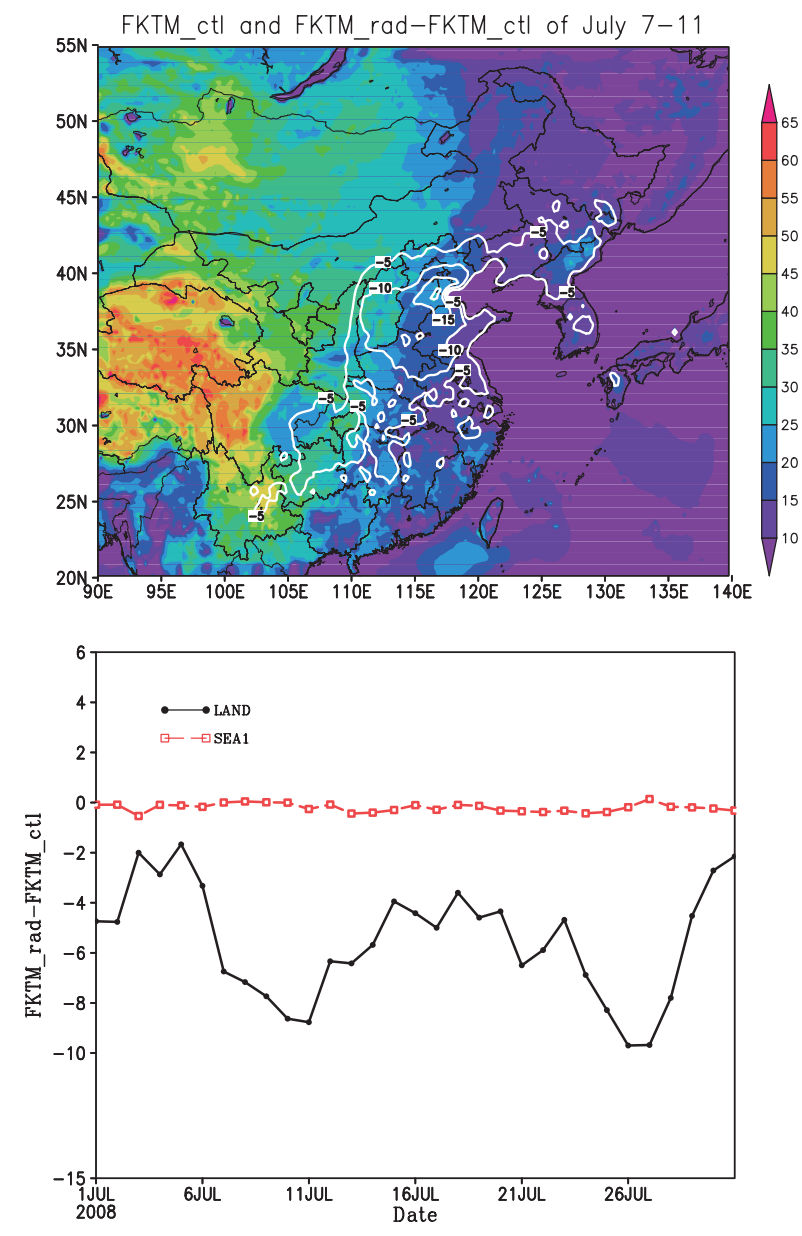

Figure 4. FKTM change $\left(\mathrm{m}^{2} \mathrm{~s}^{-1}\right)$ due to aerosol DRF: (a) mean FKTM by the CTL experiment (shaded) and FKTM difference between the RAD and CTL experiments (contour) during 7-11 July; (b) daily changes of LAND- and SEA1-averaged FKTM difference between the RAD and CTL experiments at the surface from 1 to 31 July.

\subsection{The impacts on PBLH}

PBLH is another key parameter to describe the PBL features closely related to haze and air pollution. Its impact on $\mathrm{PM}_{2.5}$ and haze was discussed in Part 1 (Wang et al., 2015). Aerosol impacts on PBLH due to DRF during the haze episode during 7-11 July are discussed in this section. Figure 5 shows PBLH changes due to aerosol DRF. Figure 5a shows that the mean daytime PBLH was as low as $400-700 \mathrm{~m}$ over the eastern Chinese mainland during the haze episode during 7-11 July. PBLH declined by about 50-300 m generally in response to aerosol DRF over this region; the PBLH difference between the RAD and CTL experiments reaches up to $200-300 \mathrm{~m}$ in 3JNS. Figure 5 b shows that daytime PBLH, especially PBLH at local noon-time (06:00 UTC), may have been diminished by aerosol DRF evidently and steadily in July 2008 , although
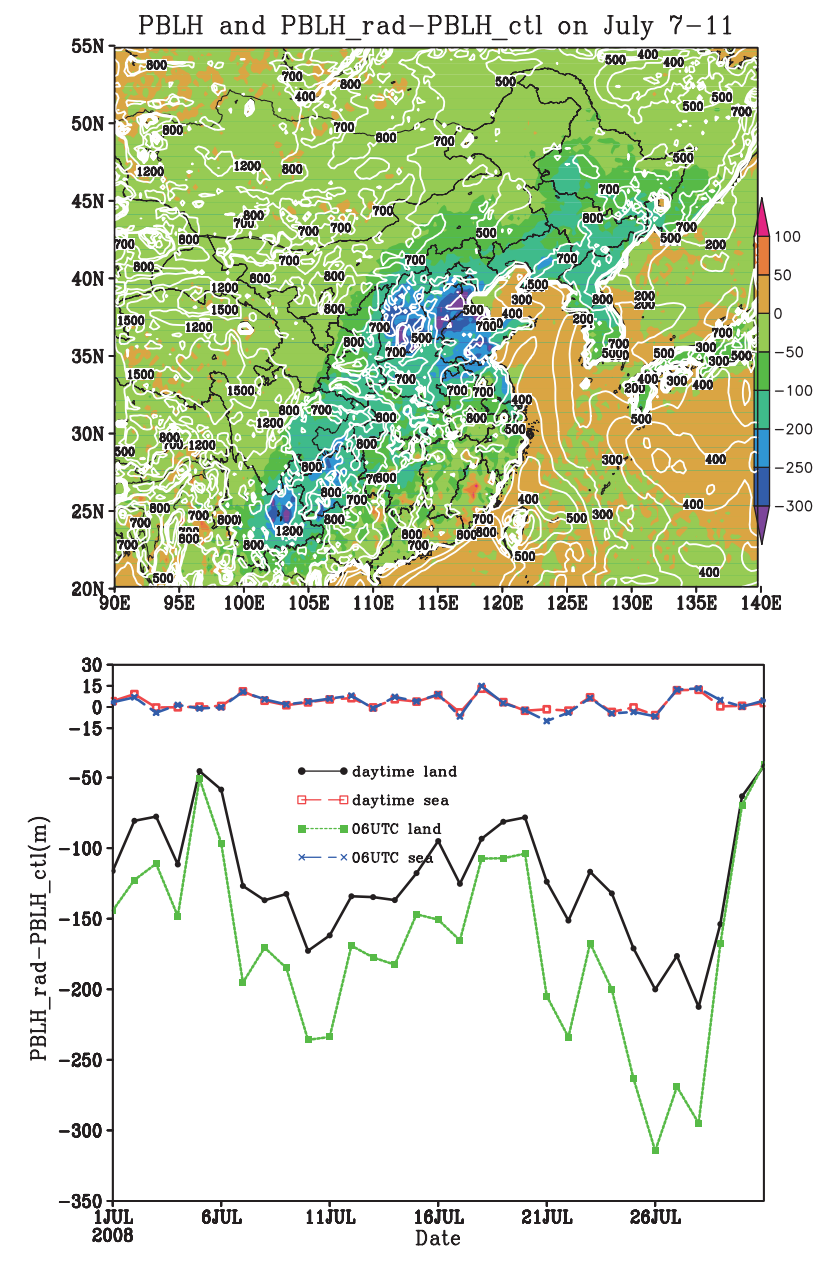

Figure 5. PBLH changes (m) due to aerosol DRF: (a) daytime mean PBLH of the CTL experiment (contour) and its difference between the RAD and CTL experiments (shading) during 7-11 July; (b) LAND- and SEA1-averaged PBLH difference between the RAD and CTL experiments from 1 to 31 July 2008.

its reduction varies with time. The PBLH reduction may have reached about $250 \mathrm{~m}$ during $10-11$ July and 250-300 m during another haze episode from 25 to 28 July. Figure $5 \mathrm{~b}$ also shows that aerosol DRF inflicts very weak impacts on PBLH over the sea with slight increases or decreases of PBLH at different times.

\subsection{The impacts on PBL wind}

The influence of surface and PBL wind fields on haze pollution is as important as, or even more important than, that of PBLH and diffusion turbulence as discussed in Part 1 (Wang et al., 2015), but the impact on PBL winds from aerosol DRF is not so strong as its impact on PBLH and diffusion turbulence. PBL wind changes due to aerosol DRF is minor and may be neglected when haze pollution is weak. The focus is on the period from 9 to 11 July with the highest $\mathrm{PM}_{2.5}$ 
and severest pollution to investigate the wind field changes due to aerosol DRF. Figure 6a shows the difference of PBLaveraged wind speed between the RAD and CTL experiments (shading) and wind vector (contour) of the CTL experiment. It can be seen from Fig. 6a that the whole PBL wind speed was increased by aerosol DRF over most of the middle and eastern Chinese mainland region, while it declined over the offshore and sea areas. Wind speed was increased from 0.4 to $0.8 \mathrm{~m} \mathrm{~s}^{-1}$ by aerosol DRF in certain parts of $3 \mathrm{JNS}$ with high particle concentration. Figure $6 \mathrm{~b}$ also indicates temporal changes in the LAND-averaged wind speed difference between the RAD and CTL experiments at the surface and PBL (950-850) hPa from 00:00 UTC on 9 July to 00:00 UTC on 12 July. Also shown is that both surface and PBL wind speed was obviously increased by aerosol DRF over this period; however, the extent of the increase in PBL wind speed was much greater than in the case of the surface wind, indicating that aerosols may impose much greater impacts on PBL winds than on surface winds.

\subsection{The impacts on the PBL air pressure pattern}

Figure 7a displays the PBL-averaged air pressure pattern during 7 to 11 July from the CTL experiment. It can be seen that subtropical high pressure controlled both eastern China and offshore regions of China. Eastern China was located on the west edge of the subtropical high with a weak southerly air flow controlling the area. This air pressure pattern is conducive to retention of haze (discussed in Part 1, Wang et al., 2015). The PBL-averaged air pressure changes due to aerosol DRF were calculated from the air pressure differences between the RAD and CTL experiments. It can be seen in Fig. 7b that the whole PBL air pressure was decreased by aerosol DRF over eastern China and its downwind region, especially over the offshore region, which resulted in the obvious weakening of the subtropical high over China's offshore and sea regions. The lessening and withdrawal eastward of the subtropical high sustained the eastward-moving cold air from the northwest and also delivered a downward flow of cold air together with some momentum from the upper atmosphere to the PBL. This seems to have helped the breaking down of the stable air pressure pattern that was controlling the retention of the haze.

\subsection{The impacts on surface $\mathbf{P M}_{2.5}$}

The reforming of the local PBL meteorology structure by aerosol DRF in turn impacts the PBL and surface $\mathrm{PM}_{2.5}$ spatial distribution, temporal changes and, perhaps, the duration time of the haze. The radiative feedback on $\mathrm{PM}_{2.5}$ by aerosols consists of the synthesized results from the PBL meteorological parameters, involving temperature, turbulence diffusion, PBLH, wind, air pressure and others.

The averaged $\mathrm{PM}_{2.5}$ loading within the PBL (contour, $\mathrm{kg} \mathrm{m}^{-2}$ ) of 7-11 July in the CTL experiment has been cal-

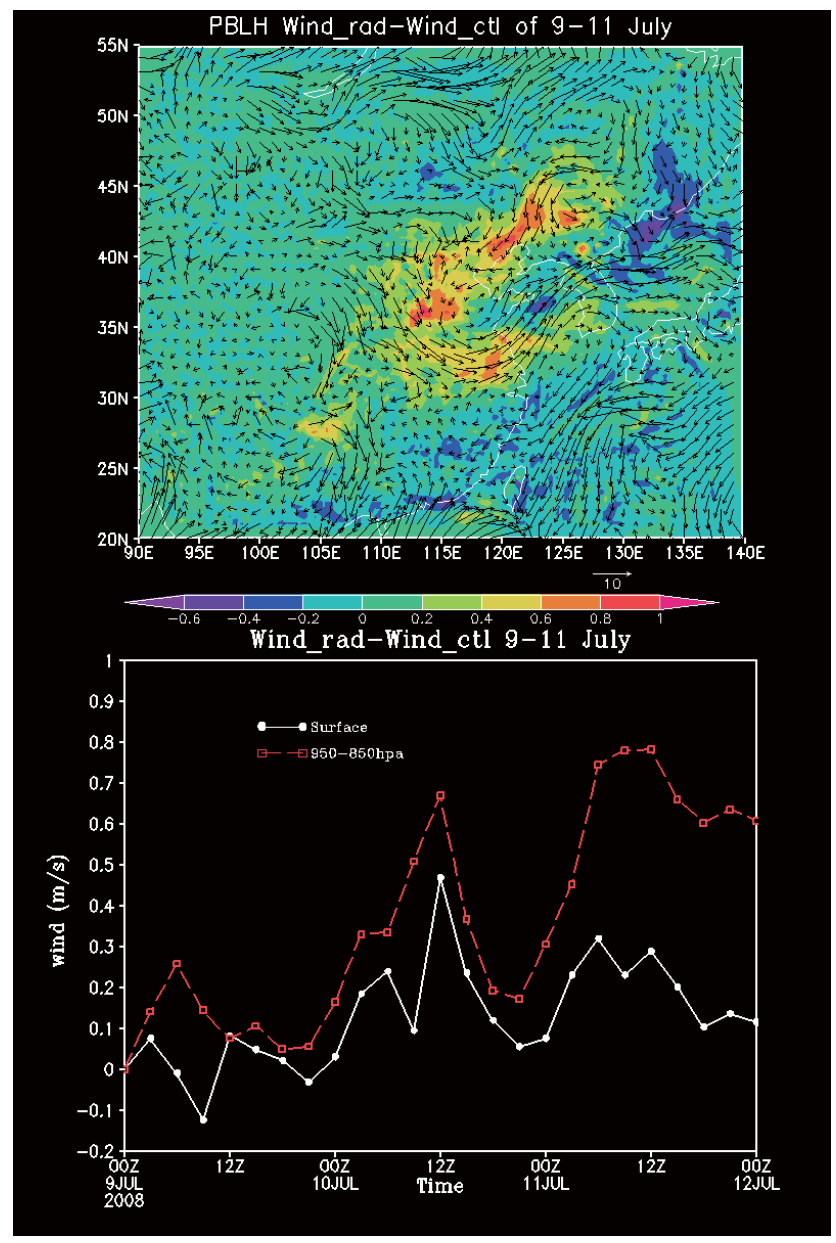

Figure 6. Wind field changes $\left(\mathrm{m} \mathrm{s}^{-1}\right)$ due to aerosol DRF: (a) the mean PBL wind vector of the CTL experiment (contour) and PBLaveraged wind speed difference between the RAD and CTL experiments (shading) from 9 to 11 July. (b) Temporal changes of LANDaveraged wind speed difference between the RAD and CTL experiments at the surface and $950-850 \mathrm{hPa}$ height from 9 to 11 July.

culated and shown in Fig. 8 together with the surface $\mathrm{PM}_{2.5}$ percentage changes attributable to aerosol DRF (shaded). It can be seen that the aerosol DRF generally increases the surface $\mathrm{PM}_{2.5}$ over eastern China, the percentage change being $>10 \%$ over most of 3JNS. The geographical location of the increasingly high percentage of $\mathrm{PM}_{2.5}$ basically correlates with the location of the high PBL $\mathrm{PM}_{2.5}$ loading. The $\mathrm{PM}_{2.5}$ increasing percentage by aerosol DRF can reach up to more than $20 \%$ over the region with the highest PBL PM 2.5 loading in 3JNS. The result indicates that the higher the PBL $\mathrm{PM}_{2.5}$ loading, the more $\mathrm{PM}_{2.5}$ might be concentrated at the surface due to aerosol DRF and in terms of the averaged condition of the haze episode. Surface $\mathrm{PM}_{2.5}$ is enhanced by about $10-20 \%$ due to aerosol DRF or even more over mideastern China.

The averaged temporal variations of surface $\mathrm{PM}_{2.5}$ of 3JNS of the CTL and RAD experiments from 7 to 13 July are 


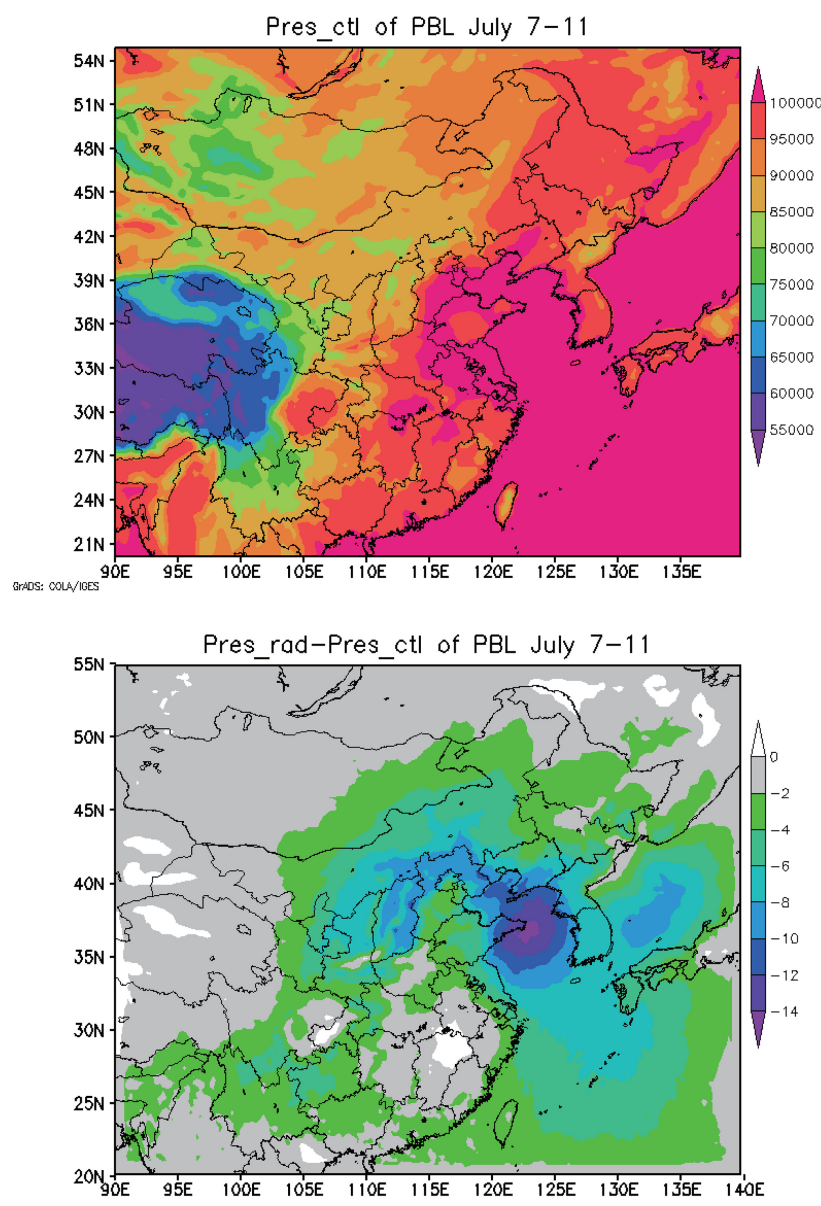

Figure 7. The PBL-averaged air pressure (hPa) from the CTL experiment (top) and its difference between the RAD and CTL experiments (bottom) of 7-11 July.

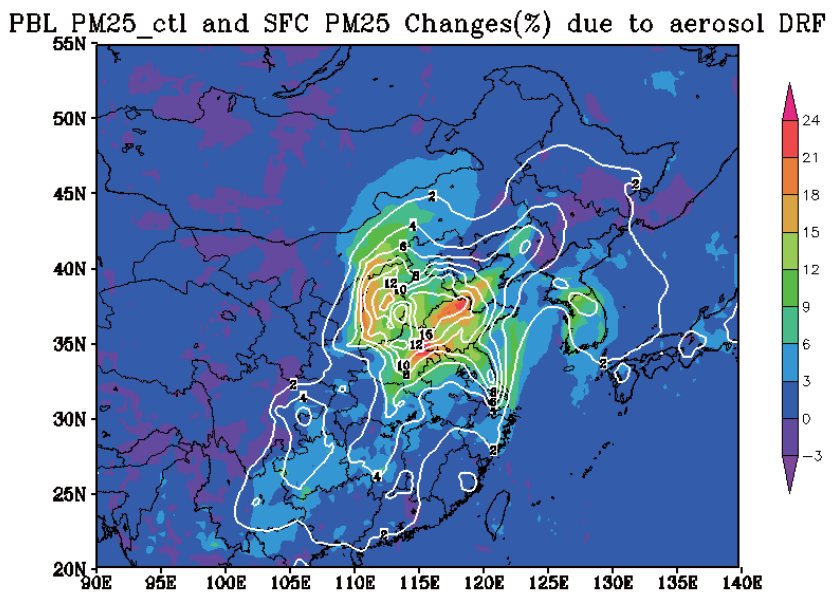

Figure 8. July during the CTL experiment and the surface $\mathrm{PM}_{2.5}$ change percentage due to aerosol DRF for 7-11 July (shaded).

also displayed and compared in order to evaluate the impacts of aerosol DRF (Fig. 9). When the surface $\mathrm{PM}_{2.5}$ concentra-

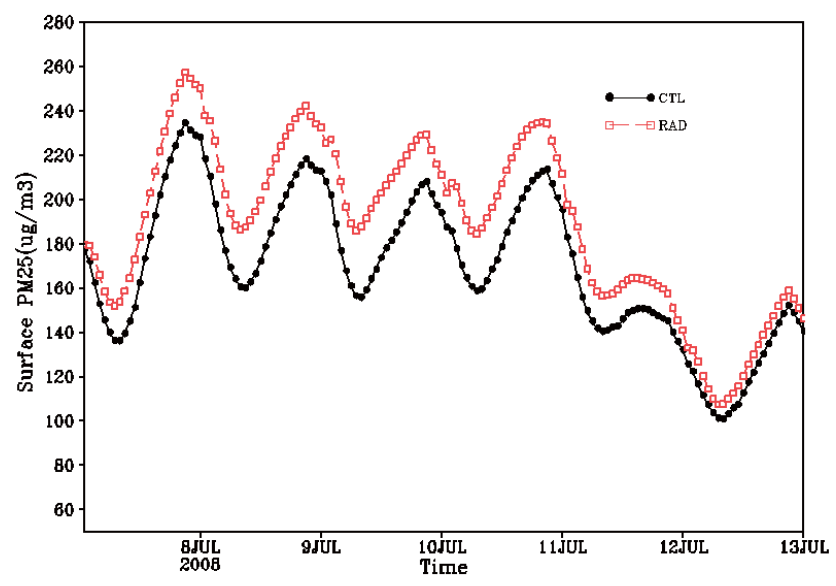

Figure 9. Temporal changes of LAND-averaged surface $\mathrm{PM}_{2.5}$ by the CTL and RAD experiments.

tion is regarded as the indicator of haze pollution, the obvious difference of PM2.5 values between the CTL and RAD experiments can be seen during the period from about 05:00 GTM on 7 July to about 18:00 GTM on 11 July. The LAND mean surface $\mathrm{PM}_{2.5}$ also remains higher than $140 \mu \mathrm{g} \mathrm{m}^{-3}$ during this period. The difference of LAND mean surface $\mathrm{PM}_{2.5}$ between the CTL and RAD experiments is small before or after that period and, at the same time, the $\mathrm{PM}_{2.5}$ values from both experiments are lower than $140 \mu \mathrm{g} \mathrm{m}^{-3}$. This indicates that aerosol DRF may have very little impact on the haze-sustaining period or keeping time of the haze episode because when $\mathrm{PM}_{2.5}$ declines below a certain level, the aerosol DRF may not be efficient enough to change the PBL meteorological circulation and then reform the $\mathrm{PM}_{2.5}$ spatial and temporal distribution.

The responses of PBL meteorology quantities to aerosol DRF relates, on the one hand, to the perturbation strength from aerosols and, on the other hand, to the thermodynamics and dynamic characteristics of these meteorological entities. In order to evaluate and order the sensitivity of these parameters to aerosol DRF, a weighting coefficient $g_{i}$ is defined as follows:

$g_{\text {i_LAND }}=\frac{\operatorname{var}(\mathrm{i})_{\text {rad_LAND }}-\operatorname{var}(\mathrm{i})_{\text {ctl_LAND }}}{\operatorname{var}(\mathrm{i})_{\mathrm{ctl}} \_ \text {LAND }}$,

where var(i) stands for different meteorological variables involving radiation fluxes, wind speed, PBLH, FKTM and $\mathrm{PM}_{2.5}$; the subscript ctl and rad identify the CTL and RAD experiments; and the subscript LAND means that all the variables are the averaged mean values of the LAND region and stand for the mean condition of 3JNS. With regard to air temperature and air pressure, the zero values have no physical meaning, $g_{i}$ is not calculated here, and only the changes due to aerosol DRF are listed. Table 1 lists the daily $g_{i}$ and the averaged $g_{i}$ of the haze episode during 7-11 July. It can be seen, therefore, that the response of the meteorological parameters to aerosol DRF from high to low is FKTM, PBLH, 
Table 1. Weighing coefficient of the response of meteorological parameters to aerosol DRF.

\begin{tabular}{lrrrrrrrr}
\hline Time & $g_{\text {flux_sw_sfc }}$ & $g_{\text {flux_lw_toa }}$ & $\begin{array}{r}\mathrm{DT}_{06} \\
(\mathrm{~K})\end{array}$ & $g_{\text {difu }}$ & $g_{\text {wind_PBL }}$ & $\mathrm{g}_{\mathrm{PBLH}}$ & $\begin{array}{l}\mathrm{DP}_{06} \\
(\mathrm{hPa})\end{array}$ & $g_{\mathrm{PM}_{2.5}}$ \\
\hline 07:00-07:24 UTC & -0.14 & -0.01 & -0.93 & -0.40 & 0.01 & -0.30 & -16 & 0.10 \\
08:00-08:24 UTC & -0.18 & -0.02 & -1.02 & -0.48 & 0.03 & -0.29 & -14 & 0.14 \\
09:00-09:24 UTC & -0.18 & -0.02 & -1.20 & -0.57 & 0.15 & -0.31 & -12 & 0.16 \\
10:00-10:24 UTC & -0.20 & -0.03 & -1.13 & -0.62 & 0.16 & -0.39 & -14 & 0.15 \\
11:00-11:24 UTC & -0.18 & -0.02 & -0.6 & -0.54 & 0.11 & -0.36 & -14 & 0.11 \\
\hline Averaged & -0.18 & -0.02 & -0.98 & -0.52 & 0.09 & -0.33 & -15 & 0.13 \\
\hline
\end{tabular}

$\Delta F_{\mathrm{SFC} \_ \text {Solar }}$, PBL wind and $\Delta F_{\mathrm{TOA}}$. The process-averaged $g_{\mathrm{fktm}}$ for $7-11$ July is -0.54 daily, ranging from -0.40 to -0.62 , and that of $\mathrm{g}_{\mathrm{PBLH}}$ is -0.33 , ranging from -0.29 to -0.39 , showing that the most important impacting mechanism from aerosol DRF is the suppression of PBL turbulence diffusion, which may lead to increasing the surface $\mathrm{PM}_{2.5}$ and to positive radiative feedback to haze pollution. $g_{\text {wind }}$ is 0.09 with daily values ranging from 0.01 to 0.16 . The PBL air pressure at 06:00 UTC fell to a mean of $15 \mathrm{hPa}$ for the period $7-11$ July and ranged from 0.12 to 0.16 , which weakened the subtropical high. The changes in both wind and air pressure may result in negative feedback to haze development. Comparing $g_{\text {wind }}$ with $g_{\mathrm{fktm}}$ and $g_{\mathrm{PBLH}}$ indicates that aerosol DRF may impose more important impacts on PBL height and turbulence diffusion than its impacts on PBL wind and air pressure. $g_{\mathrm{PM}_{2.5}}$ ranged from 0.10 to 0.16 with a mean of 0.13 for the 7-11 July period and resulted from the synthesized influence of the two opposing sides, as mentioned above, showing the final positive feedback of surface $\mathrm{PM}_{2.5}$ and haze pollution from aerosol DRF. $g_{\text {flux_sw_sfc }}$ is the weighing coefficient of change in downward solar radiation flux due to aerosols, ranging from 0.14 to 0.20 with a mean value of 0.18 . The weighing coefficient of changing TOA long-wave radiation ( $g_{\text {flux_lw_TOA }}$ ) is the smallest with a value of 0.02 , showing that total impacts on regional TOA from aerosol DRF are minor and may be neglected during haze episodes.

\section{Discussion and conclusion}

Focusing on a haze episode from 7 to 11 July 2008, two model experiments (the control experiment without calculation of aerosol-radiation effects and the RAD experiment with online calculation of aerosol-radiation interaction) are designed to evaluate aerosol direct radiative effects and feedbacks on the regional PBL atmospheric circulation related to haze formation in general and the specific haze episode in July 2008. The study involves impacts on surface SW and TOA outgoing radiation flux, temperature, PBL turbulence diffusion, wind, PBLH, air pressure pattern and $\mathrm{PM}_{2.5}$. A detailed discussion is summarized as follows:
Solar radiation flux reaching the ground is decreased by about $15 \%$ in $3 \mathrm{JNS}$ and by $20-25 \%$ in the region with the highest AOD. Only 1-3\% of long-wave outgoing flux is decreased at the TOA. Aerosol DRF has a greater impact on the ground and near-surface radiation budget than in the upper atmosphere. Aerosol cools the lower or entire PBL while warming the upper PBL or the atmosphere above it, which leads to stable stratification of the atmosphere over the middle and eastern Chinese region. In contrast, aerosol heats the PBL atmosphere weakly, causing unstable atmospheric stratification over the Chinese offshore area. On the one hand, aerosol DRF suppresses diffusion turbulence and decreases PBLH significantly over 3JNS, which enhances particle concentration on the PBL and the surface, intensifying the haze formation. On the other hand, aerosol DRF increases PBL wind speed and weakens subtropical high pressure, which contributes to the collapsing of haze pollution over this region. The impacts from the two opposite effects ultimately result in an averaged increase of $10-20 \%$ in surface $\mathrm{PM}_{2.5}$ over 3JNS by aerosol DRF but no change in the persistence time of the haze pollution. The ranking order of the impacts on meteorological parameters due to aerosol DRF according to the weighting coefficient is the turbulence diffusion, PBLH, short wave radiation flux at the surface, $\mathrm{PM}_{2.5}$, PBL wind and the TOA long-wave outgoing flux when air temperature and air pressure are not considered.

Given that most of these discussions are based on a single case of haze that occurred during the period of 7-11 July 2008 , there is clearly a need for research into more summertime haze episodes in order to support the conclusions. As haze pollution episodes occur very frequently in autumn and winter in eastern China, the PBL meteorological condition, chemical composition of aerosols and optical characteristics are quite different from those in summer, as is the radiative feedback. Finally, it should be noted that the response of different meteorological fields to aerosol DRF and their contributions to regional circulation changes also relate to their dynamic thermodynamic features. 
Acknowledgements. This work is supported by the National Basic Research Program (973) (2011CB403404), the National Natural Scientific Foundation of China (nos. 41275007 and 41130104) and the CAMS key projects (no. 2013Z007).

Edited by: X.-Y. Zhang

\section{References}

Chapman, E. G., Gustafson Jr., W. I., Easter, R. C., Barnard, J. C., Ghan, S. J., Pekour, M. S., and Fast, J. D.: Coupling aerosolcloud-radiative processes in the WRF-Chem model: Investigating the radiative impact of elevated point sources, Atmos. Chem. Phys., 9, 945-964, doi:10.5194/acp-9-945-2009, 2009.

Che, H., Zhang, X. Y., Li, Y., Zhou, Z., and Qu, J. J.: Horizontal visibility trends in China 1981-2005, Geophys. Res. Lett., 34, L24706, doi:10.1029/2007GL031450, 2007.

Che, H., Yang, Z. F., Zhang, X. Y., Zhu, C., Ma, Q. L., Zhou, H. G., and Wang, P.: Study on the Aerosol Optical Properties and their Relationship with Aerosol Chemical Compositions over three Regional Background stations in China, Atmos. Environ., 43, 1093-1099, 2009.

Che, H., Xia, X., Zhu, J., Li, Z., Dubovik, O., Holben, B., Goloub, P., Chen, H., Estelles, V., Cuevas-Agulló, E., Blarel, L., Wang, H., Zhao, H., Zhang, X., Wang, Y., Sun, J., Tao, R., Zhang, X., and Shi, G.: Column aerosol optical properties and aerosol radiative forcing during a serious haze-fog month over North China Plain in 2013 based on ground-based sunphotometer measurements, Atmos. Chem. Phys., 14, 2125-2138, doi:10.5194/acp14-2125-2014, 2014.

Cheng, Y., Canuto, V. M., and Howard, A. M.: An improved model for the turbulent PBL, J. Atmos. Sci., 59, 1550-1565, 2002.

Chou, M. D., Suarez, M. J., Ho, C. H., Yan, M. M. H., and Lee, K. T.: Parameterizations for Cloud Overlapping and Shortwave Single-Scattering Properties for Use in General Circulation and Cloud Ensemble Models, J. Clim., 11, 202-214, 1998.

Chou, M. D., Suarez, M. J., Liang, X. Z., and Michael, M.-H. Y.: A Thermal Infrared Radiation Parameterization for Atmospheric Studies, Technical Report Series on Global Modeling and Data Assimilation, NASA/TM-2001-104606, 19, America, Goddard Space Flight Center, Greenbelt, Maryland, 55, 2001.

Fast, J. D., Gustafson Jr., W. I., Easter, R. C., Zaveri, R. A., Barnard, J. C., Chapman, E. G., Grell, G. A., and Peckham, S. E.: Evolution of Ozone, Particulates and Aerosol Direct Radiative Forcing in the Vicinity of Houston Using a Fully Coupled Meteorology-Chemistry-Aerosol Model, J. Geophys. Res., 111, D21305, doi:10.1029/2005JD006721, 2006.

Grell, G. A., Peckham, S. E., Schmitz, R., McKenn, S. A., Frost, G., Skamarock, W. C., and Eder, B.: Fully Coupled "Online" Chemistry within the WRF Model, Atmos. Environ., 39, 6957-6975, 2005.

Hansen, J., Sato, M., and Ruedy, R.: Radiative Forcing and Climate Response, J. Geophys. Res., 102, 6831-6864, 1997.

Heinold, B., Tegen, I., Schepanski, I. K., and Hellmuth, O.: Dust radiative feedback on Saharan boundary layer dynamics and dust mobilization, Geophys. Res. Lett., 35, L20817, doi:10.1029/2008GL035319, 2008.
Huang, J., Minnis, P., Lin, B., Wang, T., Yi, Y., Hu, Y., SunMack, S., and Ayers, K.: Possible influences of Asian dust aerosols on cloud properties and radiative forcing observed from MODIS and CERES, Geophys. Res. Lett., 33, L06824, doi:10.1029/2005GL024724, 2006a.

Huang, J., Lin, B., Minnis, P., Wang, T., Wang, X., Hu, Y., Yi, Y., and Ayers, J.: Satellite-based assessment of possible dust aerosols semi-direct effect on cloud water path over East Asia, Geophys. Res. Lett., 33, L19802, doi:10.1029/2006GL026561, 2006 b.

Huang, J., Minnis, P., Yi, Y., Tang, Q., Wang, X., Hu, Y., Liu, Z., Ayers, K., Trepte, C., and Winker, D.: Summer dust aerosols detected from CALIPSO over the Tibetan Plateau, Geophys. Res. Lett., 34, L18805, doi:10.1029/2007GL029938, 2007.

Huang, J., Minnis, P., Chen, B., Huang, Z., Liu, Z., Zhao, Q., Yi, Y., and Ayers, J.: Long-range transport and vertical structure of Asian dust from CALIPSO and surface measurements during PACDEX, J. Geophys. Res., 113, D23212, doi:10.1029/2008JD010620, 2008.

Huang, J., Fu, Q., Su, J., Tang, Q., Minnis, P., Hu, Y., Yi, Y., and Zhao, Q.: Taklimakan dust aerosol radiative heating derived from CALIPSO observations using the Fu-Liou radiation model with CERES constraints, Atmos. Chem. Phys., 9, 4011-4021, doi:10.5194/acp-9-4011-2009, 2009.

Li, Z. Q., Xia, X. A., Cribb, M., Mi, W., Holben, B., Wang, P. C., Chen, H. B., Tsay, S. C., Eck, T. F., Zhao, F. S., Dutton, E. G., and Dickerson, R. E.: Aerosol optical properties and their radiative effects in northern China, J. Geophys. Res., 112, D22S01, doi:10.1029/2006JD007382, 2007.

Liao, H., Chen, W. T., and Seinfeld, J. H.: Role of climate change in global predictions of future tropospheric ozone and aerosols, J. Geophys. Res., 111, D12304, doi:10.1029/2005JD006852, 2006.

Perez, C., Nickovic, S., Pejanovic, G., Maldasano, J. M., and Ozsoy, E.: Interactive dust-radiation modeling: A step to improve weather forecast, J. Geophys. Res., 111, D16206, doi:10.1029/2005JD006717, 2006.

Pleim, J.: A combined local and non-local closure model for the atmospheric boundary layer. Part II: Application and evaluation in a mesoscale meteorological model. J. Appl. Meteor. Clim., 46, 1396-1409, 2007.

Ramanathan, V., Crutzen, P. J., Kiehl, J. T., and Rosenfeld, D.: Aerosols, Climate and the Hydrological Cycle, Science, 294, 2119-2124, 2001.

Santanello Jr., J. A., Friedl, M. A., and Kustas, W. P.: An empirical investigation of convective planetary boundary layer evolution and its relationship with the land surface, J. Appl. Meteor., 44, 917-932, 2005.

Shindell, D. and Faluvegi, G.: Climate response to regional radiative forcing during the twentieth century, Nat. Geosci., 2, 294-300, doi:10.1038/ngeo473, 2009.

Vogelezang, D. H. P. and Holtslag, A. A. M.: Evaluation and model impacts of alternative boundary-layer height formulations, Bound.-Lay. Meteorl., 81, 245-269, doi:10.1007/BF02430331, 1996.

Wang, J. and Christopher, A.: Mesoscale modeling of Central American smoke transport to the United States: 2. Smoke radiative impact on regional surface energy budget and boundary layer evolution, J. Geophys. Res., 111, D14S92, doi:10.1029/2005JD006720, 2006. 
Wang, H., Gong, S. L., Zhang, H. L., Chen, Y., Shen, X. S., Chen, D. H., Xue, J. S., Shen, Y. F., Wu, X. J., and Jin, Z. Y.: A new-generation sand and dust storm forecasting system GRAPES_CUACE/Dust: Model development, verification and numerical simulation, Chin. Sci. Bull., 55, 635-649, doi:10.1007/s11434-009-0481-z, 2010a.

Wang, H., Zhang, X. Y., Gong, S., Chen, Y., Shi, G., and Li, W.: Radiative feedback of dust aerosols on the East Asian dust storms, J. Geophys. Res., 115, D23214, doi:10.1029/2009JD013430, 2010b.

Wang, H., Shi, G. Y., Zhu, J., Chen, B., Che, H., and Zhao, T. L.: Case study of longwave contribution to dust radiative effects over East Asia, Chin. Sci. Bull., 30, 3673-3681, doi:10.1007/s11434013-5752-z, 2013.

Wang, H., Tan, S. C., Wang, Y., Jiang, C., Shi, G. Y., Zhang, M., and Che, H. Z.: A multisource observation study of the severe prolonged regional haze episode over eastern China in January 2013, Atmos. Environ., 89, 807-815, 2014.
Wang, H., Xue, M., Zhang, X. Y., Liu, H. L., Zhou, C. H., Tan, S. C., Che, H. Z., Chen, B., and Li, T.: Mesoscale modeling study of the interactions between aerosols and PBL meteorology during a haze episode in China Jing-Jin-Ji and its near surrounding region - Part 1: Aerosol distributions and meteorological features, Atmos. Chem. Phys., 15, 3257-3275, doi:10.5194/acp-15-32572015, 2015

Yu, H., Kaufman, Y. J., Chin, M., Feingold, G., Remer, L. A., Anderson, T. L., Balkanski, Y., Bellouin, N., Boucher, O., Christopher, S., DeCola, P., Kahn, R., Koch, D., Loeb, N., Reddy, M. S., Schulz, M., Takemura, T., and Zhou, M.: A review of measurement-based assessments of the aerosol direct radiative effect and forcing, Atmos. Chem. Phys., 6, 613-666, doi:10.5194/acp-6-613-2006, 2006.

Zhang, X. Y., Sun, J. Y., Wang, Y. Q., Li, W. J., Zhang, Q., Wang, W. G., Quan, J. N., Cao, G. L., Wang, J. Z., Yang, Y. Q., and Zhang, Y. M.: Factors contributing to haze and fog in China, Chin. Sci. Bull., 58, 1178-1187, doi:10.1360/972013-150, 2013 (in Chinese). 